\title{
A Study on the Risk of Small and Medium Enterprises Financial Outsourcing in China
}

\author{
Fang Fang \\ Accounting School, Jiangxi University of Finance and Economics, Nanchang, China \\ Email: Fiona0910@yeah.net
}

How to cite this paper: Fang, F. (2016) A Study on the Risk of Small and Medium Enterprises Financial Outsourcing in China. Open Journal of Social Sciences, 4, 1-18. http://dx.doi.org/10.4236/jss.2016.410001

Received: September 8, 2016

Accepted: September 27, 2016

Published: September 30, 2016

Copyright $\odot 2016$ by author and Scientific Research Publishing Inc. This work is licensed under the Creative Commons Attribution International License (CC BY 4.0).

http://creativecommons.org/licenses/by/4.0/

\begin{abstract}
The domestic enterprises began to face fiercer competition, which under the rapid development in the global economy today and the market increasingly competitive. During the government work report of 2015, Prime Minister Li Keqiang first proposed that encouraging people to start their own business and to make innovations, so that can be a new engine of economic development under the China's New Normal. The leader of the economic reform is the micro, small and medium enterprises. In addition to the support of policy from the government for SMEs in financing, the SMEs should try to reduce the cost of capital by business management. The SMEs also need to create unique core competitiveness, in order to gain a foothold in the ever-changing global market. Outsourcing as one of the important means to reduce operating costs, has been adopted by more and more enterprises. As an auxiliary function of enterprise, financial outsourcing is beneficial to reduce the management cost and improve the efficiency of management. It can also help SMEs focus on the core competitiveness of ascension. When SMEs enjoy the benefits of such financial outsourcing, they are also associated with the risk of outsourcing. If the enterprise does not have a clear understanding and effective management with the outsourcing risk, it will lead to the enterprise cannot reach the purpose of outsourcing, also called the failure of outsourcing activities. Therefore, while the SMEs choose financial outsourcing, they must have the analysis and evaluation system of outsourcing risk. In this paper, based on the above analysis of the background, we study the risk of SMEs financial outsourcing. And after introducing the content and the status quo of financial outsourcing, we discuss the financial risk when the enterprise using financial outsourcing, and classify the risk, then measure the risk response, which in order to offer the decision-making basis for the successful implementation of financial outsourcing activities.
\end{abstract}




\section{Keywords}

Small and Medium Enterprises, Financial Outsourcing, Risk

\section{Introduction}

\subsection{Studies on the Background and Significance}

Since the 21th century, the trade of integration and globalization in the world economy has become increasingly evident, and the market competition has broken the boundaries and geographical constraints. The competition becomes more and fiercer so that domestic enterprises have to survive in harsher environments. Small and medium-sized enterprises (SMEs) are the pillar of the national economy. The rapid development of Chinese SMEs has made significant achievements over 30 years from the reform and opening up. Besides, SMEs has become an important force in economic and social developments. However, SMEs have been facing serious problems of survival. According to the statistics, the average life expectancy of Chinese private enterprises is only 2.9 years. The key to maintain the survival of SMEs lies in the company's financial management. With more and more refined social division of labor, social collaboration becomes more common. The professional division of labor-outsourcing-has adapted to the social economic development. Many companies including multinational enterprises established their leading position in the market by outsourcing their business process, such as AMD, Apple and so on. There are diverse forms of business process outsourcing including production outsourcing, software outsourcing and financial outsourcing. Financial outsourcing model has been recognized by more and more companies in enterprise financial management. The application of financial outsourcing model means that one company outsources a part or all of business process work to external professional companies from its finance department. Not only can enhance the corporate financial management, and also help enterprises to invest more energy in their core business in order to strength their core business competitive advantage through the professional financial outsourcing services provided by the specialized outsourcing company.

Financial outsourcing is originated in Western countries, it's a financial strategy management model that one enterprise outsources some certain matters or some processes in financial management to external professional agency, which purpose is put more energy into its core business to strengthen its core competitiveness and make it easier to survive in the industry (see [1]). The first to benefit from the financial management outsourcing should be the British Petroleum (BP). BP outsourced its accounting business in North Sea oil drilling project to well-known consulting firm Accenture, and BP saved half of its cost due to the professional management provided by Accenture. The advantage of this cost made a huge improvement of company's core competitive. Western countries have been at the forefront of financial outsourcing, and financial outsourcing is another rapidly developing industry after IT outsourcing in western countries. As of 2010, the global financial outsourcing output has excessed 54 billion 
dollars, accounting for about $7 \%$ in the global outsourcing business. However, financial outsourcing has not been generally adopted in China; it is still in the early stages of development. The companies which adopt financial outsourcing mostly are foreign subsidiaries or joint ventures based, such as Unilever, Microsoft, Johnson \& Johnson, and so on. One of the reasons is that domestic enterprises are not familiar with the content and the form of financial outsourcing. Moreover, there are many doubts about financial outsourcing application because of the lack of understanding about the comprehensive benefits and related financial risks brought by financial outsourcing. With respect to large enterprises, financial outsourcing is more suitable for SMEs, because the professional financial processes are favorable to the development of SMEs. Agent returns, bookkeeping, financial management and consulting for SMEs are mostly used in financial outsourcing model currently.

However, everything has two sides, like a double-edged sword; there are both advantages and disadvantages. As a new financial strategy management model, financial outsourcing cannot make the exception. With the professional outsourcing provider, financial outsourcing can help company makeup their weakness and help they to reduce management costs and capital costs, improve the management efficiency and the management effectiveness. At the same time, financial outsourcing released much energy so that enterprises can be more concentrate on their core business areas and fully tap the core competitiveness. But there are also a lot of business risks during the financial outsourcing. For business management decision-making, how to accurately identify, effectively analyze and scientific assess outsourcing in order to make valid management on outsourcing risks is the issue that worthy be serious consideration and scrutiny. Therefore, it's extremely important to research and make effective analysis on corporate finance outsourcing risks. To gain a foothold in the global competitive market for Chinese companies and to promote a sustainable development for Chinese national economy, there has a very important significance to make correct and comprehensive understandings of the financial benefits and risks about SMEs' financial outsourcing.

\subsection{Literature Review}

1) Foreign Research Status

"Outsourcing" is formally proposed by Prahalad and Hamel (see [2]) in their article named The Company's Core Competitiveness published in Harvard Business Review in 1990, which opened the prelude to the foreign scholars' theoretical study of outsouring.

Strassman (1995) believed very few companies considered financial outsourcing by strategic reasons in practice. And the statistics showed that the real motivations of financial outsourcing enterprises always are the financial difficulties that those enterprises encountered.

Brandes (1997) pointed out that the main motivation for enterprises adopting outsourcing is the willing to reduce costs, while manager also have come to realize that outsourcing is a strategic tool to gain competitive advantage.

Cedric Read et al. (2001) pointed out, CFO has become pivotal in the management 
network of company's value. The differentiation of financial functions makes the transactions can be done through shared services to operate by remote or fully outsourced, in order to enhance the value the company and improve the company's wealth.

Accenture and the Economist Intelligence Unit (2003) were focused on financial outsourcing, they reached the following conclusions through case study: First, choosing a company accept the financial outsource made significant savings in terms of costs. It helps the financial sector get rid of the tedious repetition of the daily workload, besides, it allows the company to focus on the overall review and reengineering businesses processes as well as facilitate the implementation of the reform program. The second is that financial outsourcing can enhance the transparency of financial outsourcing.

Lan Benn and Pearcy (2004) considered that outsourcing can provide enterprises with a triple advantage: strategic advantages, financial advantages and benefits associated with the brand. Outsourcing can bring efficiency in practical sense for the company, and announced "pretty" reports to the public.

Clements and Donnellan (2008) pointed out from the perspective of CFO, the fundamental to obtain outstanding achievement lies in the ability to use technology, an advanced technology that enables company to obtain long-term success and produce the greatest commercial value. With the combination of technology and outsourcing, companies can standardize the financial process and get the expected return on investment through the establishment of effective business alliance to acquire new capabilities and resources. They also reminded that there would be a large business process outsourcing services provider (MSP) in the future, MSP would link every service center to establish a global network, and outsourcing companies can achieve the trend of global resource sharing by the networked outsourcing center.

Gree, Youngblood and Gray (2009) divided outsourcing into five stages from the perspective of outsourcing processes: outsourcing decisions, the choice of the service provider, the management of supplier relationship, the management of outsourcing services transfer, the monitoring and evaluation of service supplier's performance. And they also put forward reasonable suggestions to implement outsourcing.

2) Domestic research Status

The theoretical study of financial accounting outsourcing started late in our country, domestic scholars' researches about SMEs' financial accounting outsourcing rise in recent years, and those researches are mainly started by three respects: professional organizations, clients, service level and so on.

Zheng Lingyan (2007) believed that there are mainly three respects in the financial outsourcing in current China:

a) Few professional organizations, and lack of the ability to undertake business;

b) The range of service objects is relatively narrow; and

c) The business level is low.

Zhou Jianxia (2008) pointed out that the financial accounting outsourcing can help companies reduce costs, reduce investment spending and control cost structure. Besides, service providers can be considered as the external think tank team of the enter- 
prise. So, the enterprise can share the service provider's financial knowledge and technology which can reduce risk and help the company to standardize its financial accounting processes and standards. Accordingly, the financial accounting outsourcing can promote the enhance of the company's value.

However, according to Yu Weidong's (2008) analysis, he pointed out that outsourcing does not necessarily reduce costs. Most outsourcing service providers' backstage facilities are located in large cities while most SMEs are located in small cities or rural towns. Therefore, outsourcing may not be able to reduce the cost of financial management, so the current problems to be solved are the development of outsourcing service providers in small and medium cities.

Yu Qiang (2010) believed that China's credit system is still relatively weak, it depends on the rules and regulations in order to develop credibility. The purpose of financial accounting outsourcing is maximizing the reduction of cost, complying with the regulations, consolidating the industry, reducing the complexity of the environment and access to new technologies and management portal. If hit by the credit crisis, the company's cost world increase inevitable and the outsourcing would be meaningless. Therefore, enterprises should develop good financial details of the contract before implementing outsourcing.

We can conclude from the literature review, the foreign and domestic research is relatively mature on IT outsourcing and logistics outsourcing. While the research on financial outsourcing is relatively limited and it mostly focus on the impact of outsourcing, advantages and disadvantages and policy recommendations. Besides, those research methods are mostly normative study and just stay at the theoretical level, those researches lack enough empirical research. There have no systematical risk identification and risk prevention strategies on the previous research about SMEs' financial outsourcing.

\subsection{Research Ideas and Structure}

1) Research content

The main research contents of this paper are as follows:

a) Summary of domestic and international financial outsourcing risk management research status;

b) The theory of enterprise financial outsourcing and SME criteria in China;

c) Analyzing and classifying the risk of financial outsourcing in SMEs;

d) The proposed measures and suggestions for risk management and prevention of financial outsourcing of SMEs.

2) Research methods

This paper mainly uses the literature to summarize the research status at home and abroad, comprehensive analysis of previous research results, combined with the actual situation of domestic small and medium-sized enterprises, the process analysis method, comparison, induction and deduction, analysis and synthesis of the various research methods, combining financial outsourcing risk theory and practical application, for our 
country small and medium-sized enterprise financial outsourcing risk aversion provides practical guidance.

\section{SME Criteria in China and Definition of Financial Outsourcing}

\subsection{SME Criteria in China}

Different countries have different standard of SME, and generally from two aspects of quality and quantity to definition SME. Quality index contains the organizational form and structure of enterprises and the status in their industry and the way of financing and so on. Quantity index includes the number of employees and assets and so on. While the quantity index is much easier to access than the quality index, most country choose quantity index to division. As the journal of the American law (2001) define SME criteria as no more than 500 employees. The European Union and the UK also take the quantity index as the principal thing, qualitative indicators as auxiliary at the same time.

SME criteria in China have experienced several stages of development, and now, it is entering the stage which is more perfect then past. SME criteria of our country are mainly according to the turnover and total assets, and different industry has different standards. In 2011, the Industry and Information Ministry, the National Bureau of statistics, the national development and Reform Commission, Ministry of Finance jointly issued "the notice on the issuance of small and medium-sized enterprises designated standards", the notice classified fifteen sectors, which are the agricultural, forestry, animal husbandry and fishery industry; construction industry; wholesale trade; transportation industry; retail industry; accommodation industry and catering industry, information industry, software and information technology service industry, warehousing industry; postal services; real estate development and management, property management, leasing and business services sector and other specified industries. And the notice also defined SME from three aspects, which are the turnover, practitioners and total assets of the enterprises.

\subsection{Definition of Financial Outsourcing}

Financial outsourcing is a management pattern that enterprise outsources part or all of the financial management and accounting business process to a professional financial-management firm.

Current financial outsourcing can be divided into traditional financial outsourcing and financial outsourcing based on modern network. Traditional financial outsourcing mainly to break down the entire financial management activities according to the needs of enterprises into several modules such as general ledger accounts, current accounts management, payroll, fixed asset management, reporting systems, tax returns and other modules. And then outsourcing these modules which enterprise is not good at manage or does not have a comparative advantage to those who lead the industry standards in this aspect of the professional bodies. Such as, outsourcing the financial management to banks or other financial institutions, outsourcing accounts receivable to billing-comp- 
any.

Financial outsourcing based on modern network is the use of modern financial applications, which the financial application platform provided by financial services Network Company (such as ASP, namely application service providers). By sign the contractual agreements, all or part of the financial business systems outsourcing to service providers. The service provider alternative perform financial operations processes and production functions of the financial information business through franchise sites on the Internet, however, analyze the functions of decision-making remain with the entity senior financial management staff to perform, in the meanwhile, service providers need ensure the quality of financial information and give the necessary advice or guidance. Financial outsourcing based on modern network is an advanced form of the network technology popularization of traditional financial outsourcing development. The outsourcing of financial functions forms an organic logical connection through the network technology platform. This approach can also achieve the overall outsourcing financial functions, and high efficiency.

With the development of economic globalization, this new management model, financial outsourcing, gradually develops and become mature. After long-term theoretical research, and combined with various types of literature, the theoretical basis of domestic and foreign, financial outsourcing business can be categorized as follows: the core competence theory, transaction cost theory and value chain theory.

1) The core competence theory

In 1990, the American scholar Gary Hamel and C.K. Praharad first proposed outsourcing in the essay "The Core Competences of the Corporation". That is, in the case of limited resources within the enterprise, to its non-core business subcontracting by way of contract to other companies, while he is focused on the development of the most competitive core business to strengthen the competitiveness of enterprises.

2) Transaction cost theory

British economist Ronald Coase introduced the concept of transaction costs in the "Nature of the Firm", published in 1937. In his saying, there are two kinds of transaction costs, one is market transaction costs; the second is the internal transaction costs. By comparing the two costs, companies should be the level of costs, then choose lower transaction costs.

3) Value chain theory

Value chain theory was born in 1985, presented by the American Michael E.Porter, he believes the enterprise value chain created by based activities and auxiliary activities. the competition between enterprises is not constitute by a part of a separate competition, but complete competing of value chains between enterprises, and the ultimate purpose of the value chain is to maximize profits.

\section{The Risk Categories of SMEs' Financial Outsourcing}

\subsection{The Process of Financial Outsourcing}

This article will use the process analysis method to drawn the various stages of business 
finance outsourcing into a continuous flow chart, to abstract business operations into an intuitive flow chart, according the importance of each part of the operation to classification the type of risk. The flow diagram of generalized process when an enterprise implementing financial outsourcing shown as follows Figure 1.

\subsection{The Features of SMEs' Financial Outsourcing}

Financial outsourcing for SMEs is a double-edged sword. It can reduce business costs, improve enterprise management level and enhance core competitiveness of enterprises, at the same time, due to the late development of financial outsourcing in our nation and the imperfect of laws and regulations; there are some "Chinese-style" questions with SMEs:

1) Lack of communication with the service provider.

Most Chinese SME managers are the founder of the enterprise. Due to the prevailing conditions, these entrepreneurs have not received good financial literacy training, even not received a good quality education. Therefore they cannot be properly understood on "financial outsourcing". One improper understanding is the money should not be exposed. That means they do not believe that professional financial outsourcing contractor, and they would not outsourcing the company's financial information, it would lead to less effective communication between the enterprise and the outsourcer; the other is shut their ears after outsourcing. In financial outsourcing failure, most financial information leakage and poor cost control are caused by the blind trust in the outsourcer. In that situation, long-term financial outsourcing and blindly rely on out sourcing would lead to increasing poor financial capacity, once the cooperation with

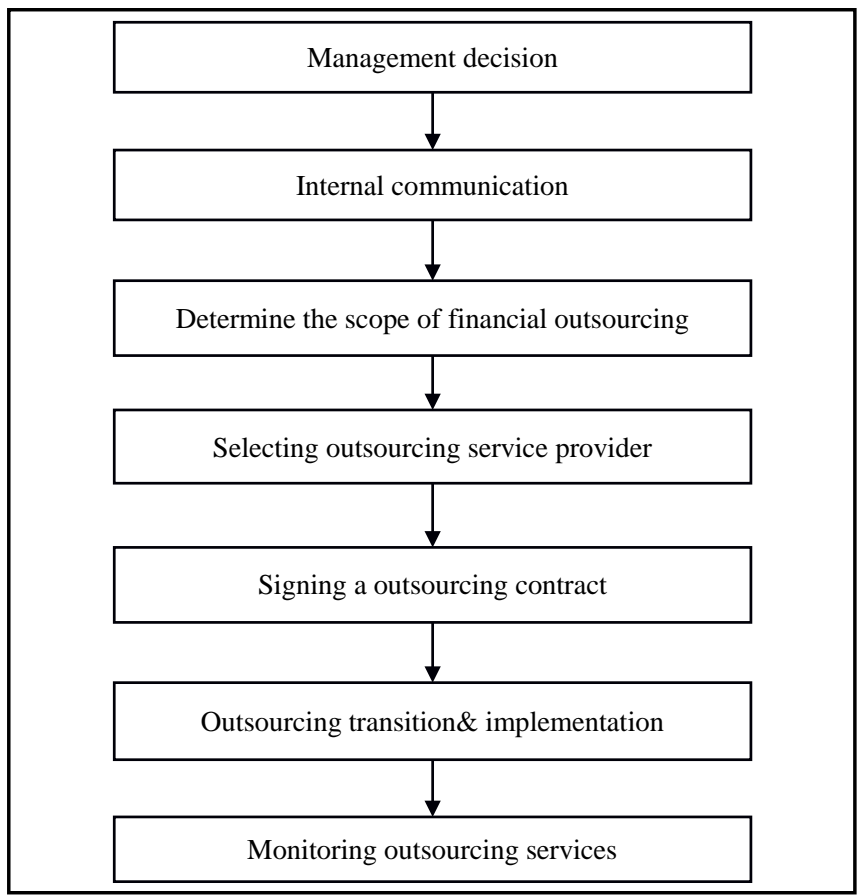

Figure 1. The process of Financial outsourcing implementation. 
the outsourcer is interrupted; it is difficult to return to normal in the finance.

2) Lack of understanding of outsourcing service provider before cooperation.

Financial outsourcing of SMEs failed, in partly because of the absence outsourcing service provider for investigation.

Assessment index of outsourcing service providers are commonly classified as professional and technical knowledge, business management skills, behavior management, social relations, service innovation, process improvement capabilities, and key account development skills and so on. Among them, technical knowledge and business management capability of the outsourcing service provider is particularly important. Just think, if a SME outsourcing it's financial to a service provider whose professional level is very low and do not know how to manage business. It wouldn't bring the expected results, let alone improvement of the core competitiveness for enterprises. It is a common problem for SMEs that lack of investigation of outsourcing service provider before financial outsourcing.

3) Pay too much attention to the cost while ignore the quality of service.

An important reason for SMEs authorized financial outsourcing is financial outsourcing can save cost by partly or whole of the financial work done by external professional service organizations. On the one hand, it can save hired labor costs of financial personnel, on the other hand, the cost of financial information of the software and hardware construction can be saved, at the same time, the enterprise can get more specialized, high-quality financial outsourcing services. Based on the consideration of cost, SMEs often want to obtain service at the lowest price, so it will be possible to drive down the price of financial services. For that reason, financial outsourcing service providers may to undertake financial outsourcing, in receiving low price and drop low financial service quality, eventually benefited neither of the two parties.

4) Lack of flexibility.

Lack of flexibility mainly reflected on poor communication and poor timeliness. Many chief of SMEs have misconceptions that financial outsourcing means be free with financial issues. In their concept, financial outsourcing service providers do all of the financial operations, what they care about is only the profit on the financial report. The true is, the service providers generally server the company or feedback financial information at regular intervals. This would lead a disconnection between finance account and management, in that case, there would be a certain lag with identify and solve problems, and the financial analysis would be restricted.

\subsection{Key Risk of Financial Outsourcing for SMEs}

According to the process above the enterprise implementation of financial outsourcing, combined with the characteristics of SMEs' financial outsourcing in our country, obtained the key risk of financial outsourcing, which include: decision risk, communication risk between two parties, risk of purview of outsourcing, outsourcing service provider selection risk, the contract risk. The following will carry out a detailed analysis of the risk which is referred above. 


\subsubsection{Decision Risk}

The risk factor refers to the possible gain and the risk that the enterprise may face when the financial outsourcing strategy is implemented. It can be divided into two kinds of risks: one is the risk of outsourcing decision-making errors; second is the risk of cost outpace.

As the leadership of the party, should consider the strategic decision of the outsourcing process, at the same time, it is necessary to formulating some discussion questions. Such as, is this financial outsourcing suitable for us? What is the definition of outsourcing success? What is the main purpose of financial outsourcing? What processes should be outsourced and what processes should not be outsourced? What is the cost of outsourcing? Whether in compliance with the principle of cost and benefit? How much time will it take to fully implement the outsourcing? How long will it take to achieve the goal of financial outsourcing? What skills are needed to be retained in the process of outsourcing? What skills should be focused on in the selection of the contractor? Whether it will encounter the moral problems of enterprises? What kind of psychological impact will be caused to the employees who have stayed or moved out?

These issues are the barriers facing by the leadership of enterprises. Therefore, to achieve the initial goal of financial outsourcing, contractors need a decent, strategic leadership team, with scientific and effective management to ensure financial outsourcing to achieve substantial success.

\subsubsection{Communication Risk between Two Parties}

Communication risk between two parties can be divided two types of risk, one is the risk with internal employees understanding, namely when the enterprise in the implementation of the project of financial outsourcing, lack of necessary communication and coordination between enterprise management and enterprise internal staff, it would be a reservations or even opposing attitude from internal staff on financial outsourcing project implementation, in another word, the staff does not support financial outsourcing strategy resulted in the policy difficult to implement, or paid more of the cost to implement. Thus, when the enterprise is in the implementation of financial outsourcing program, the enterprise needs to communicate with the internal staff to coordinate, so that employees can fully understand the company's decision. Only after obtaining the support of employees, especially the financial staff, can the implementation of the financial outsourcing strategy to implement the smooth implementation of the relevant processes, and achieved initial results.

Secondly, there is a risk of information communication between the contractor and the subcontractor. The factors that influence the risk are as follows:

1) The staffs think if the financial outsourcing, it is likely to make financial information leaked out, so as to cause serious impact on the enterprise. As a result, employees may hide important information when they provide information to the outsourcing provider, which leads to the outsourcing companies cannot play their own functions, and ultimately affect the quality of service.

2) The differences of corporate culture, style and values of the two parties also can 
influence trust between each other. In the process of information communication, the original information is collected by the enterprise and analysis of financial information is performed by outside contractors, since they response for independent part from each other, it is difficult to monitor each other, which will lead to mutual suspicion.

3) On the basis of mutual trust, the communication risk is still affected by information transfer. If the process when original information provided by enterprises transfer to outsourcing or the process when outsourcing providers feedback of financial information analysis to the employer in the presence of time delays, there will be great risk to the enterprise management decision.

\subsubsection{Risk of Purview of Outsourcing}

Risk of purview of outsourcing refers to the risk of the enterprise in the implementation of financial outsourcing strategy, decide which financial business processes need to outsource, the scope of outsourcing, the degree of outsourcing and so on. The enterprise should define the scope of outsourcing according to the actual situation of the company.

At the same time, in the scope of outsourcing selection should also consider whether it will cause leaked of enterprise the key technology and the advantages of resources. The core competitiveness of enterprises that the long-term formed is a combination of the skills and knowledge which is unique for every enterprise. It is also the key competitive advantage to support the past, present and future, so that enterprises can obtain the active core ability in competition environment. If the enterprises do not make longterm strategic choice for the mode of the future financial, then in the process of financial outsourcing, companies are likely to lose its core competitiveness, which will bring risk cannot be estimated. Some scholars believe that: due to some enterprises' weak financial management capabilities, the development of the enterprises is restricted, the implementation of financial outsourcing can save the cost of financial management, access to accurate financial analysis. But for long-term interests, if the enterprise's financial department did not make full use of the advanced financial processing technology and experience, and did not have reasonable planning of the outsourcing scope, the enterprises will lose the opportunity to improve financial management capability. What's the worst, once enterprises no longer cooperate with outsourcing service providers, enterprises cannot adapt to the new accounting environment, and it would be in a state of disarray? The purpose of outsourcing is to strip out those values of the relatively low content of functions, so that enterprises can focus on their core competitiveness of the business section, if the cart before the horse can backfire.

\subsubsection{Outsourcing Service Provider Selection Risk}

Because our country hasn't exactly set up the quality standard of the service provider, the information asymmetry will lead to the choice of inappropriate service providers. At this stage, the role of outsourcing services to the accounting firm to play. From Table 1, we can see that the ranking of the top three are is cooperation between Chinese and foreign firms, four domestic and foreign cooperation of firm's total revenue in 2015 
Table 1. Comprehensive evaluation of accounting firm.

\begin{tabular}{cccccccc}
\hline $\begin{array}{c}\text { Accounting } \\
\text { Firm }\end{array}$ & Ranking & $\begin{array}{c}\text { Evaluation } \\
\text { Score }\end{array}$ & $\begin{array}{c}\text { Self-employment } \\
\text { Revenue }\end{array}$ & $\begin{array}{c}\text { Other } \\
\text { Revenue }\end{array}$ & $\begin{array}{c}\text { Revenue } \\
\text { Score }\end{array}$ & $\begin{array}{c}\text { Other } \\
\text { Score }\end{array}$ & $\begin{array}{c}\text { Penalty } \\
\text { Points }\end{array}$ \\
\hline PWC & 1 & 1710.96 & $371,348.24$ & & 1000 & 716.96 & -6 \\
Deloitte & 2 & 1663.51 & $313,092.45$ & & 969.14 & 700.37 & -6 \\
E \& Y & 3 & 1657.16 & $283,323.15$ & & 951.07 & 706.08 & 0 \\
RuiHua & 4 & 1649.29 & $306,202.57$ & $30,267.84$ & 966 & 691.29 & -8 \\
CCPA & 5 & 1648.38 & $290,695.72$ & $30,441.60$ & 956.66 & 691.72 & 0 \\
KPMG & 6 & 1614.94 & $235,071.87$ & & 917.31 & 703.63 & -6 \\
CPAs & 7 & 1541.13 & $150,590.03$ & & 836.78 & 704.35 & 0 \\
ShineWing & 8 & 1504.78 & $128,288.93$ & & 807.79 & 696.99 & 0 \\
Baker Tilly & 9 & 1483.71 & $121,705.73$ & $26,323.53$ & 800.21 & 683.50 & 0 \\
Zhi Tong & 10 & 1479.80 & $119,627.22$ & & 795.10 & 684.70 & 0 \\
\hline
\end{tabular}

Data source: Institute of Certified Public Accountants of the Ministry of Finance [2015] 46.

to $1,258,459.56$ million Yuan, in the top ten firms, foreign accounting firm business accounted for than for $54.25 \%$. Although in recent years, domestic firms in the audit business accounted for larger, but from the overall data visible, foreign accounting firms in the non-audit business accounting is still large and SMEs cannot afford the big four international accounting firms of high fees, only ability is limited, the general level of outsourcing business in China. Outsourcing service providers have a very important role in the whole process of the implementation of financial outsourcing. First, the quality of personnel, professional and technical level of outsourcing service providers determines the level of service providers to provide services in the process of outsourcing. Secondly enterprise implementation of financial outsourcing strategy, very easy to form dependence on outsourcing service providers, and enterprises need to take full account of the huge cost of the financial management of the business transfer, and frequent replacement of the financial management service providers may cause the risk of information leakage (see [3]).

Enterprises in the choice of outsourcing service providers will face a greater risk of decision-making level. If enterprises in the selection of a good service provider, between service providers and enterprises can be for good communication and coordination, help the enterprise to deal with the related problems, optimize business processes, you can bring a lot of extra income to the enterprise. In turn, if the service provider fails to provide good service, between the enterprise and the communication difficulties, not only can help companies improve efficiency, optimize business processes, but will bring huge risk to the enterprise, even to push the enterprise management financial abyss. That's the risk of outsourcing.

\subsubsection{Contract Risk}

When enterprises in the choice of service providers, it is impossible to fully grasp all of the information of service providers, there is a certain asymmetry of information, service providers often promise better, but in the specific implementation process out- 
sourcing, often occur this or that problem, bring the enterprise great risk. Not only cannot reach the purpose of the implementation of financial outsourcing business, it will hinder the development of enterprises.

Contract risk refers to the signing of the relevant enterprises in the financial outsourcing contract with the outsourcing service provider; there may be some loopholes in the contract or contract fraud. As enterprises in the signing of the contract, may be agreed upon specific financial business processes are not standardized, or the relevant provisions of the agreement is not clear, the late provision of services under a contract outsourcing service provider may not refuse to provide specifications or unclear or related services quality of service cannot reach the intended purpose. The risk of the contract are likely to behave in a range of outsourcing the content, quality of service, trade secrets and other aspects of the revised contract is no specific agreement, it may impose an legal disputes and litigation or other hidden administrative costs hidden.

\section{Risk Response Strategies}

In view of the five risks above of financial outsourcing for SMEs, we can treat those risks from three directions, which is reduced risk, transfer risk, and risk retention.

\subsection{Risk Reduction Strategy}

During the enterprise implementation of financial outsourcing strategies, outsourcing risk is always throughout the entire financial process outsourcing which is inevitable. So in order to ensure their own interests for the companies, to ensure the successful implementation of financial outsourcing strategies, companies need to take appropriate measures to reduce the risk of financial outsourcing. Reducing the risk of financial outsourcing companies in general are by taken careful selection of outsourcing service providers to develop a detailed contract, strengthen communication and coordination between service providers and the like. The following will describe in detail.

\subsubsection{Careful Selection of Outsourcing Service Providers}

Through the above analysis of the risk categories, when choose business outsourcing service providers, companies should consider more aspects of these various factors, after a comprehensive analysis, I think we should focus on the factors from the following aspects. First, considering the quality of service, service providers' service level, whether the service commitment can achieve the desired purpose financial outsourcing enterprises, whether service providers have the strength to help solve real business problems which is the first thing we need to consider when we make the choice of service providers . Secondly, companies should consider the price service providers offer. The important reason of financial outsourcing enterprises is to implement strategies is to reduce costs. So in the case of service providers to provide the same level of service, companies should consider the price. Thirdly, companies should consider the degree of specialization of service providers to provide services. While at the time if the service providers provide long service for a number of service companies, then the service provider is more familiarity with the process of financial business. The higher the practical expe- 
rience, the higher the degree of specialization, enterprises should choose such kind of service provider.

\subsubsection{Develop Detailed Contracts}

Financial outsourcing companies need to determine implement strategies. After the determination for outsourcing business type and business content, it is necessary to prepare a detailed service contract or service agreement with the service provider. In this service contract, the parties need to be clear of responsibilities and rights.

First, the contract should include the implementation of specific business outsourcing, prices of financial outsourcing, contract implementation deadlines. The contract should also make a number of other conventions suitable for special needs explanation according to the actual situation of enterprises. As the enterprises and outsourcing service providers should discuss a clear revenue allocation and risk sharing funds operational management issues in the contract. By restricting of contracts, between companies and outsourcing service providers, there is a establishment of a mechanism of mutual restraint which is on revenue distribution, clear agreement proportion of risksharing, clear agreement between businesses and service providers on the rights and obligations of the risks and benefits of a reasonable balance. Secondly, financial management and business enterprises share a lot of internal trade secrets. These secrets will bring very serious consequences to the enterprise, so that in the development contract, service providers must be fully taken into account in information security, information security measures, as well as the responsibility borne by service providers in case of information leakage. In view of this, the contract should make special provisions for confidentiality and security of information. While financial outsourcing enterprises enjoy convenient services, they should be free from information leakage troubles. Finally, due to the financial impact of the external environment by outsourcing, the contract should respond to internal and external measures when the environment changes, taking into account the principle of when changes occur. This ensures that the normal execution of financial outsourcing contracts.

Between enterprises and outsourcing service providers, they should take full account of the development of the contract possible influencing factors, and to distinguish between the responsibilities, rights, benefits and so on. However, cooperation between enterprises and outsourcing service providers is based on a relationship of trust. If only considered in the formulation of the contract breach, breach of agreed terms of the ratio of large accounts, and less incentives for compliance, it will dampen enthusiasm for service providers to provide services, and negative attitude problems will occur in the implementation of the outsourcing process. Therefore, taking into account the liability for breach of contract and incentives should be developed in the two sides to achieve a win-win business based on the following objectives consistent with both goals.

\subsubsection{Strengthen Communication with the Service Provider}

During the implementation phase of outsourcing corporate finance, corporate finance team has not lost the original role. They do not show it to business process outsourcers 
and have nothing to do. They have active communication and coordination with outsourcing service providers. Then outsourcing service providers will conduct their business successfully by corporate finance activities. According to the characteristics of financial outsourcing, companies should enhance communication the following aspects with outsourcing service providers.

1) Corporate finance activities is so important for the enterprise that when enterprises implement financial outsourcing, they need to strengthen mutual trust, actively take the initiative with the business side staff and communicate and strengthen exchanges with the outsourcing of service personnel, enhance mutual trust, establish a good strategic partnership, actively cooperate to avoid a sudden interruption of business impact.

2) Business side personnel should also provide the necessary assistance and enable outsource service providers to be better familiar with the business environment, to enable them be more quickly into the financial management of the business to do better service to enterprises.

3) Financial management staff of business side also need do process supervision and monitoring the of entire financial outsourcing services business, particularly do focus monitoring in the financial outsourcing which has a greater risk factor in the carried out process. Being active to exchange views with service providers is a way to avoid or reduce the risk of the loss of financial outsourcing risk to a minimum.

In short, in particular financial implementation, the business side needs to continue to strengthen communication with outsourcing service providers. Think about the solution of outsourcing service problems timely and coordinate to avoid major problems in bilateral cooperation. Ensure cooperation between the two sides stability, and ensure controllability of financial outsourcing risks.

\subsection{Risk Transfer Strategy}

Enterprises can not only take appropriate measures to reduce the financial risk of outsourcing, but also can transfer the financial outsourcing risk by some suitable measures. For enterprises, the common used strategies to transfer the risk are insurance, financial guarantee and contracts and financial agreements (see [4]).

\subsubsection{Transfer Outsourcing Risk by Insurance}

There are some financial outsourcing risks that are inevitable for enterprise, so the company can purchase insurance from the non-affiliated third party of the outsourcing service, in order to transfer the potential loss to other companies. When companies purchase a commercial insurance from third party, they need pay a certain amount of the premium of insurance. And then, the third party would transfer the expected risk of financial outsourcing in the process of outsourcing implementation. If there is a loss in the process of financial outsourcing implementation, the third party would compensate the economic losses according to the contract agreement and responsibility. Compared to other risk response plan, the insurance to transfer the risk is the highest efficiency. So, transfer the risk through the purchasing of insurance is a common method. How- 
ever, the use of insurance requires the enterprise to pay a certain amount of the premium to a third party in addition. So companies need compare the risk and cost, and make the decision after a comprehensive analysis.

The company must do the cost account before using insurance strategy to transfer outsourcing risk. For example, suppose all the value of financial outsourcing risk is 300 million when the company chooses financial outsourcing service according to the financial risk measurement. So it would be necessary for the company to purchase the insurance when insurance premium is much lower than the entire risk value, while it is no need to purchase the insurance when premium is higher than risk value and the company could select other cheaper ways to reduce the risk.

\subsubsection{Transfer Outsourcing Risk by Contracts and Financial Agreements}

With the draft of a detailed contract, enterprises can reduce the financial outsourcing risk efficiently. In addition, enterprises can also add several limit agreements to the financial outsourcing contract or agreement in order to transfer the relevant outsourcing risk. With the help of negotiation between enterprises and outsourcing service providers, they can set specific terms which is protectable to transfer the risk to the outsourcing service provider. Make full particulars of the factors which would cause risk during the implementation of financial outsourcing, and specify the risk responsibility for each party or specify the proportion of risk for each party to undertake. Enterprises can transfer all or part of the financial risk to the outsourcing service provider.

The company pays a relative lower cost for adopting the risk transfer method of contracts and financial agreement. This approach is suitable for SMEs, they can determine the details of the contract and agreement with the negotiation and transfer all or part of the risk to outsourcing service provider. Besides, the cost for this approach is relative low to the enterprise, because the company needn't to pay additional cost to transfer the risk. While the outsourcing service provider need to undertake the risk of outsourcing service, the cost associated with the financial outsourcing may rise and the company pay the hidden cost for the outsourcing service. In actually, the essence of this method to transfer the risk is as the same as the previous one, the only different is enterprises purchase the insurance from the outsourcing service providers instead of from the third party. Compared to purchasing insurance from third party, purchasing from service provider is much cheaper. Since the service providers bear all or part of the financial outsourcing risk, the quality of its services and the control of risk will have a significant improve because of the restrict of contract. Therefore, companies can pay little to exchange for large returns.

\subsubsection{Transfer Outsourcing Risk by Third Party Guarantee}

Enterprises can also reduce outsourcing risk and reduce financial risk by the way of risk guarantee to transfer all or part of the risk to the guarantor except for the previous two methods. Guarantee can be divided to assurance guarantee and property guarantee. Assurance guarantee is based on personal credit, and the guarantor must have a certain social status, stable income and several discursive power. The property guarantee ach- 
ieves by property guaranteed bonds and the company can transfer the risk to a third party through guarantee. Property guarantee can be divided into two types: collateral guarantee and pledge guarantee.

\subsection{Risk Retention Strategy}

While dealing with the financial outsourcing risk, some risk cannot be eliminated or reduced by transferring, and there even has some risks cannot be expected during the implementation of financial outsourcing process. So, under such situations, enterprises need to adopt risk retention strategy to deal with and undertake the potential risks.

For enterprises, they should consider all of these three methods comprehensively during the implementation of the financial outsourcing service. Make the most suitable decision according to the general analysis of type of risk, probability of occurrence and potential loss. Choose the lowest cost method when ensuring the risk level is acceptable for the company.

\section{Conclusions and Expectation}

In this paper, the risk identification, management and coping strategies of enterprise financial outsourcing are studied by using the theory of financial outsourcing and risk management. Through the recognition of financial outsourcing risks, the paper gives the Countermeasures of outsourcing risk and gives some suggestions. Through the research of this paper, we can draw the following conclusions:

1) In the planning of enterprise financial outsourcing, on the outsourcing risk identification should use a variety of ways to combine the way of risk identification, according to the enterprise of the industry characteristics and their own situation, choose the appropriate way of risk identification. The first step in the implementation of financial outsourcing risk identification enterprises, only complete and comprehensive recognition of the risk of corporate financial outsourcing, to be able to correctly carry out the risk analysis and response.

2) In the analysis of financial outsourcing risk, through the qualitative analysis of financial outsourcing risks in the enterprises and the overall risk level is determined and further risk segments, to cause the risk factors identification, provide more accurate reference information for enterprise decision makers.

3) Due to the internal and external environment of the enterprises are facing is changing, financial outsourcing risk will changes with the changes of internal and external environment, so enterprises in the implementation process of financial outsourcing and need to continuous monitoring of the risk, process monitoring need outsourcing risk re identification and ranked in order of importance, and coping strategies of adjustment according to the results of the risk identification.

4) For financial outsourcing risks in the enterprises of various coping strategies, enterprises need to select the appropriate coping strategies according to their actual situation, comprehensive use reduce risk, risk transfer, risk retained strategy, make enterprise financial outsourcing risks to a minimum. 
Because the author's ability is limited, and the research time is short, so the research of this paper has a lot of problems, and the risk of enterprise financial outsourcing can be further studied.

1) The research of this paper has carried on the general and universal research to the enterprise financial outsourcing risk, has not carried on the classification research to the enterprise's industry, the enterprise nature and so on. And different industries, different types of enterprises to carry out financial outsourcing risk factors are very different, the risk identification system, risk indicators, and so there is a big difference. So the research on the financial outsourcing risk system of different enterprises is a subject that needs to be studied deeply.

2) In this paper on the small and medium-sized enterprise financial outsourcing risk measurement no further study, and in the actual operation of the enterprise and need to the risk management needs to collect a large number of relevant risk data, using a suitable mathematical analysis method, for the identification of risk quantitative analysis. Quantitative analysis can be more scientific and reasonable to identify and sort out the risk of financial outsourcing, so as to provide more accurate reference information for decision makers.

3) The of financial outsourcing risk were detailed analysis and description, but for enterprises, the implementation of financial outsourcing, it is necessary to consider not only the outsourcing risk, but also need to consider the demand and cost benefit of a variety of factors. This paper of enterprise outsourcing decision content description analysis is not comprehensive enough, no comprehensive analysis and decision factors of enterprise financial outsourcing.

Financial outsourcing is a trend in the development of enterprises, regardless of for SMEs or outsourcing service providers, financial outsourcing risk are a very important topic, has the enormous practical significance.

\section{Acknowledgements}

I acknowledge financial support from the Social Science Planning Project of JiangXi Province (Grant No. 14GL05).

\section{References}

[1] Zhu, D.Q. (2009) The Study of Financial Outsourcing: Experiences from Abroad and Practices from China. Production Study, 35-38.

[2] Prahalad, C.K. and Hamel, G. (1990) The Core Competence of the Corporation. Harvard Business Review, 79-91.

[3] Loh, L. and Venkatfaman, N. (1992) Determinants of Information Technology Outsourcing: A Cross-Sectional Analysis. Journal of Management Information Systems, 7-24.

[4] Lai, W.D. (2009) The Risks and Legal Protection of Company Outsourcing. Management and Technique of SMEs, 16-19. 
Submit or recommend next manuscript to SCIRP and we will provide best service for you:

Accepting pre-submission inquiries through Email, Facebook, LinkedIn, Twitter, etc. A wide selection of journals (inclusive of 9 subjects, more than 200 journals)

Providing 24-hour high-quality service

User-friendly online submission system

Fair and swift peer-review system

Efficient typesetting and proofreading procedure

Display of the result of downloads and visits, as well as the number of cited articles

Maximum dissemination of your research work

Submit your manuscript at: http://papersubmission.scirp.org/

Or contact jss@scirp.org 